\title{
A IMPORTÂNCIA DA POPULARIZAÇÂO DAS PLANTAS ALIMENTICIAS NÃO CONVENCIONAIS (PANC): INFORMAÇÃO, SAÚDE E QUALIDADE DE VIDA
}

Carmen Lúcia da Silva1, Delton Mendes Francelino², Raiane Elisabete Barbosa³

1 Graduanda do Curso Superior de Nutrição do Instituto Federal de Educação Ciência e

Tecnologia do Sudeste de Minas Gerais- Campus Barbacena.

Pesquisadora do Centro de Estudos de Ecologia Urbana.

E-mail: carmensilvasbq@gmail.com

2 Professor na Graduação em Ciências Biológicas e Coordenador do Centro de Estudos em Ecologia Urbana no Instituto Federal de Educação Ciência e Tecnologia do Sudeste de Minas Gerais - Campus Barbacena.

${ }^{3}$ Graduanda do Curso Superior de Nutrição do Instituto Federal de Educação Ciência e Tecnologia do Sudeste de Minas Gerais- Campus Barbacena.

Pesquisadora do Centro de Estudos de Ecologia Urbana.

Recebido em: 15/08/2020 - Aprovado em: 15/09/2020 - Publicado em: 30/09/2020 DOI: 10.18677/EnciBio_2020C1

\begin{abstract}
RESUMO
A pesquisa teve como objetivo central apresentar e descrever de forma prática algumas das PANC (Plantas Alimentícias Não Convencionais) que são alimentos ainda pouco utilizados na gastronomia comercial e que carregam grande valor histórico e cultural, além de, muitas vezes, serem extremamente nutritivas. Ainda pouco conhecidas, esses insumos são produzidos em pequena escala e têm poucos estudos relacionados a eles, apesar de sua importância já conhecida e da alta potencialidade nutricional e gastronômica. A pesquisa foi dividida em três fases distintas; (1) revisão bibliográfica; (2) métodos e discussão; (3) espécies das plantas identificadas e caracterizadas. Para que esses produtos sejam integrados à cultura alimentar atual brasileira é necessário difundir o conhecimento a cerca deles, provocando um interesse que será formador do mercado consumidor. O quadro teórico em anexo baseou - se em autores como Ranieri, (2017), espera - se que com o conteúdo descritivo das espécies dessas plantas encontradas na região do pé da Serra da Mantiqueira localizada no Campo das Vertentes especificamente de Barbacena (MG), possa ser difundindo esses saberes, sendo os líderes de cozinha os principais divulgadores com um papel diferenciado na sociedade. A metodologia utilizada foi baseada em revisão literária, tendo a relevância ao tema analisado como único critério de inclusão, a seleção de fontes foi realizada por meio de diversas bases de dados, sendo os descritores utilizados na busca: PANC, plantas alimentícias não convencionais.
\end{abstract}

PALAVRAS-CHAVE: alimentação alternativa; cadeia produtiva; cultura alimentar. 


\title{
THE IMPORTANCE OF THE POPULARIZATION OF NON-CONVENTIONAL FOOD PLANTS (PANC): INFORMATION, HEALTH AND QUALITY OF LIFE
}

\begin{abstract}
The main objective of the research was to present and describe in a practical way some of the PANC (Non Conventional Food Plants) that are still little used in commercial gastronomy and that carry great historical and cultural value, in addition to often being extremely nutritious. Still little known, these inputs are produced on a small scale and have few studies related to them, despite their already known importance and high nutritional and gastronomic potential. The research was divided into three distinct phases; (1) literature review; (2) methods and discussion; (3) plant species identified and characterized. In order for these products to be integrated into the current Brazilian food culture, it is necessary to spread the knowledge around them, provoking an interest that will shape the consumer market. The attached theoretical table was based on authors such as Ranieri (2017), it is expected that with the descriptive content of the species of these plants found in the foot of the Serra da Mantiqueira located in Campo das Vertentes specifically in Barbacena (MG), it can be spreading this knowledge, the kitchen leaders being the main promoters with a different role in society. The methodology used was based on a literary review, with relevance to the analyzed theme as the only inclusion criterion, the selection of sources was carried out through several databases, the descriptors being used in the search: PANC, unconventional food plants.

KEYWORDS: alternative food; productive chain; food culture.
\end{abstract}

\section{INTRODUÇÃO}

Segundo o Ministério do Meio Ambiente, o Brasil tem o título de País com a maior biodiversidade do planeta, possuindo mais de $20 \%$ do número total de espécies da Terra (BRASIL, 2020a). Isto se traduz em uma grande diversidade de plantas com potencial para aproveitamento na alimentação humana. Considerando a biodiversidade previamente mencionada, isso acarreta a perda do grande potencial que existem nas chamadas plantas alimentícias não convencionais (PANC).

Caracterizadas pelo uso limitado, seja por motivos culturais, dificuldades de produção, desconhecimento da possibilidade de uso, dentre outros motivos, as PANC já existem em diversos ambientes na forma de produtos secundários ou chamadas ervas daninhas, invasoras e outros termos que sugerem não possibilidade de consumo (KINUPP, 2007).

Já existem pesquisas que investigam o valor nutricional de algumas PANC, como o chamado "umbigo de bananeira" (SILVA et al., 2014), ora-pro-nóbis, dentre outros, e observa-se que devido, em parte, à natureza de "praga" de algumas destas plantas, caracterizada pela alta resistência e grande ocorrência espontânea, podem apresentar um valor nutricional elevado, além de serem de fácil cultivo.

Dentro do estado de Minas Gerais, especialmente na zona rural, existem populações que preservam algumas destas PANC, já que muitas vezes estas fazem parte da alimentação destes grupos há mais de uma geração (BARREIRA et al., 2015). Apesar desta localização de uso e conhecimento, várias destas plantas já foram catalogadas e analisadas, porém, ainda não têm seu consumo difundido para além do local de origem. 
Vale mencionar que já existe um esforço por parte do Estado de Minas Gerais para a preservação da biodiversidade brasileira dentro do Ministério do Meio Ambiente, que envolve a proteção de espécies nativas do País (BRASIL, 2020b), e, por consequência, das PANC. Além disso, com a recente relevância dada a estas também na mídia (CASA E JARDIM ON-LINE, 2017), em eventos (SMERALDI, 2020) e restaurantes existe certamente um maior enfoque na sua proteção (BAHLS; KRAUSE, 2017), porém, falta disponibilidade destes alimentos à população.

A movimentação para popularizar e expandir a presença das PANC na alimentação já ocorre por parte das grandes cozinhas, que propõem a utilização destes alimentos não apenas por seu sabor único, mas também por suas propriedades medicinais de relevância histórica e cultural. O líder/chef de cozinha torna-se, a força motora do movimento de preservação do patrimônio cultural alimentar de um povo, contra a força uniformizadora do mercado, uma vez que, ao expor estes produtos ao mundo e demonstrar seu potencial, criam uma demanda que será entendida (MARQUES, 2020).

A popularização das PANC, tornando-as parte do consumo da população em geral, se integrará na sociedade como um todo e permanecerá vivo na cultura alimentar popular, perpetuando a tradição e a memória que a acompanha, (REVISTA EXAME, 2019). Os nutricionistas e prestadores de serviços de alimentação se tornam, então, figuras de grande importância na definição dos hábitos de consumo alimentar da população brasileira.

A diminuição do consumo de alimentos em casa e o crescimento de consumo de alimentos pré-preparados e instantâneos é um novo hábito da população o que pode prejudicar a qualidade de vida se a alimentação não for de qualidade, podendo comprometer a manutenção da saúde (FIESP, 2017). Seja em pequena ou larga escala, na difusão do conhecimento sobre as PANC, trazendo à tona sua existência e potencial para o público geral, criando um interesse que toma a forma de um mercado consumidor (SEBRAE, 2020). Grandes produtores e indústrias, vendo então, uma oportunidade de comercialização destes produtos, podem tomar o lugar dos pequenos produtores e herdeiros diretos neste processo de preservação (MARQUES, 2020).

Observa-se dentre o êxodo rural da população brasileira, que marca uma preponderância de centros urbanos na composição populacional (IBGE, 2019), tendência que apresenta, historicamente, crescimento acelerado e significa acesso reduzido da maior parte da população a hortas, canteiros e pequenos produtores locais. O acesso a insumos apresentados apenas por pequenos produtores, que já não estão completamente integrados à cadeia produtiva, se torna cada vez mais limitado (EMBRAPA, 2018).

As PANC são integrantes da alimentação brasileira desde tempos remotos, acompanhadas de um processo hereditário de envolvimento, cultivo e consumo que implica, além da herança física de plantas, mudas e sementes, na transmissão do conhecimento associado a seu consumo seguro (BARREIRA et al., 2015), ou seja, mesmo que exista a possibilidade de cultivo em horta para qualquer indivíduo, até mesmo em espaços confinados e de área altamente limitada (DORNELES et al., 2011), há riscos associados ao consumo destes produtos sem as informações adequadas.

A união dos potenciais nutricional, cultural e gastronômico das PANC cria a necessidade de encontrar uma forma coerente com o atual cenário da cultura alimentar 
de difundir as práticas de cultivo e consumo destes alimentos (MARQUES, 2020). Temse então, como objetivo do presente artigo, realizar uma análise das especiais de PANC e suas características na região de Barbacena (MG), com grande área agrícola rural produtiva, além da popularização e relevância das cozinhas e de espaços gastronômicos na disseminação do uso dessas plantas, sua importância cultural, preservação e viabilização como produtos comerciáveis.

Para elaboração do artigo foram considerados pesquisas e artigos para melhor compreensão do assunto, buscando assim apresentar o consumo das PANC como alternativa de alimentação saudável e mais nutritiva de baixo custo. Apresentar também a importância histórica e cultural das PANC e sua amplitude de usos, além de potenciais vantagens para a subsistência de comunidades de baixa renda, tornam a preservação dessas plantas inegavelmente importante, além de seu valor econômico.

\section{Procedimentos Metodológicos}

\section{MATERIAIS E MÉTODOS}

O estudo foi realizado nos meses de maio, junho e julho de 2020 e, para o mapeamento da região foram utilizadas áreas agrícolas regional para identificar e estimar áreas com cobertura agrícola rural produtiva na região de Barbacena (MG), onde foram catalogadas espécies de PANC popularmente conhecida junto ao meio rural local tendo como finalidade a identificação das espécies possibilitando a elaboração de uma tabela teórico descritiva das PANC mais conhecidas, para a classificação das espécies foi utilizado o conhecimento local baseado na cultura e história popular, conhecimentos locais passados entre gerações.

Após a identificação dessas plantas apresentadas no estudo, foi gerada uma tabela teórica descritiva, em que foi possível a identificação e descrição de diversas plantas locais populares, e que estão entre os cardápios já testados por cozinhas ou centros gastronômicos, além de comercializadas em feiras livres locais e cozinhas da população do campo.

Para o estudo e reflexão sobre a relação entre a popularização e disseminação dos saberes sobre as PANC e a qualidade de vida em Barbacena (MG), recorreu-se a documentos oficiais governamentais como o Plano Municipal de Saneamento Básico de Barbacena (MG) de 2014, no qual constam dados oferecidos pelas Unidades Básicas de Saúde como parte das Estratégias de Saúde da Família.

Vale ainda ressaltar que para o levantamento dos dados relacionados às populações de regiões periféricas rurais com produção agrícola tradicional, foi necessário o uso de informações de órgão como o IBGE (2019).

\section{Caracterização da área de estudo}

A proposta central do estudo foi analisar e caracterizar espécies de PANC na cidade de Barbacena (MG) localizada ao pé da Serra da Mantiqueira, a cidade de Barbacena (MG) está a 1160 metros de altitude e a cerca $170 \mathrm{~km}$ de distância de Belo Horizonte (MG), a área compreende $788,001 \mathrm{Km}^{2}$ de extensão e encontra-se na mesorregião mineira denominada "Campo das Vertentes" IBGE (2019), para a viabilidade do estudo pesquisado foi analisado como amostragem um distrito pertencente ao município onde ainda preserva-se a tradicional cultura agrícola do campo e valores conservados há gerações. 
A cidade possui clima ameno e frio e ficou conhecida nas décadas de 1970 e 1980 como a "Cidade das Rosas". A região estudada apresenta histórico na produção agrícola rural, que se deve, em grande parte, à ocupação dos imigrantes na região, o clima e altitudes favoráveis.

O estudo foi realizado na comunidade do Faria, um distrito do município brasileiro de Barbacena (MG), no interior do estado de Minas Gerais, possuindo uma área total de $68,4 \mathrm{Km}^{2}$, com uma população de 546 habitantes (IBGE, 2010), está localizado a 24 minutos e com 13,2 Km de distância do município de Barbacena (MG), sendo considerada uma área com produção rural agrícola.

Esta pesquisa foi desenvolvida metodologicamente a partir de três fases distintas: (1) revisão bibliográfica; (2) métodos e discussão; (3) espécies das plantas identificadas e caracterizadas.

A fase 1 teve como fator principal a revisão bibliográfica onde foram pesquisados e estudados temas como Plantas Alimentícias não Convencionais, popularização e conhecimentos sobre as mesmas, foram considerados autores e manuais como: Dorneles et al., (2010); Silva et al., (2014); Barreira et al., (2015); Brasil, (2017); FIESP (2017); Kinupp, (2017); Krause (2017); Ranieri (2017); revista como Casa e Jardim Online (2017); Smeraldi (2017); IBGE (2010 e 2019); SEBRAE (2019); Marques (2020).

A fase 2, posterior ao processo de revisão bibliográfica, constituiu-se basicamente no levantamento de espécies das PANC conhecidas popularmente e com tendência histórica regional, apontando um crescimento significativo de acesso a maior parte da população em hortas, canteiros e pequenos produtores locais.

Por fim, a fase 3 propôs, a partir dos dados de estudos obtidos nas fases anteriores, a construção de uma tabela para melhor compreensão das espécies de PANC popularmente conhecidas por alto valor nutritivo e medicinal.

\section{RESULTADOS E DISCUSSÃO}

As PANC mais conhecidas no Distrito do Faria no município de Barbacena - MG encontram-se no Quadro abaixo:

QUADRO 1 - PANC identificadas na região do Faria distrito da cidade de Barbacena (MG) e algumas características com descrição na obra de RANIERI (2017).

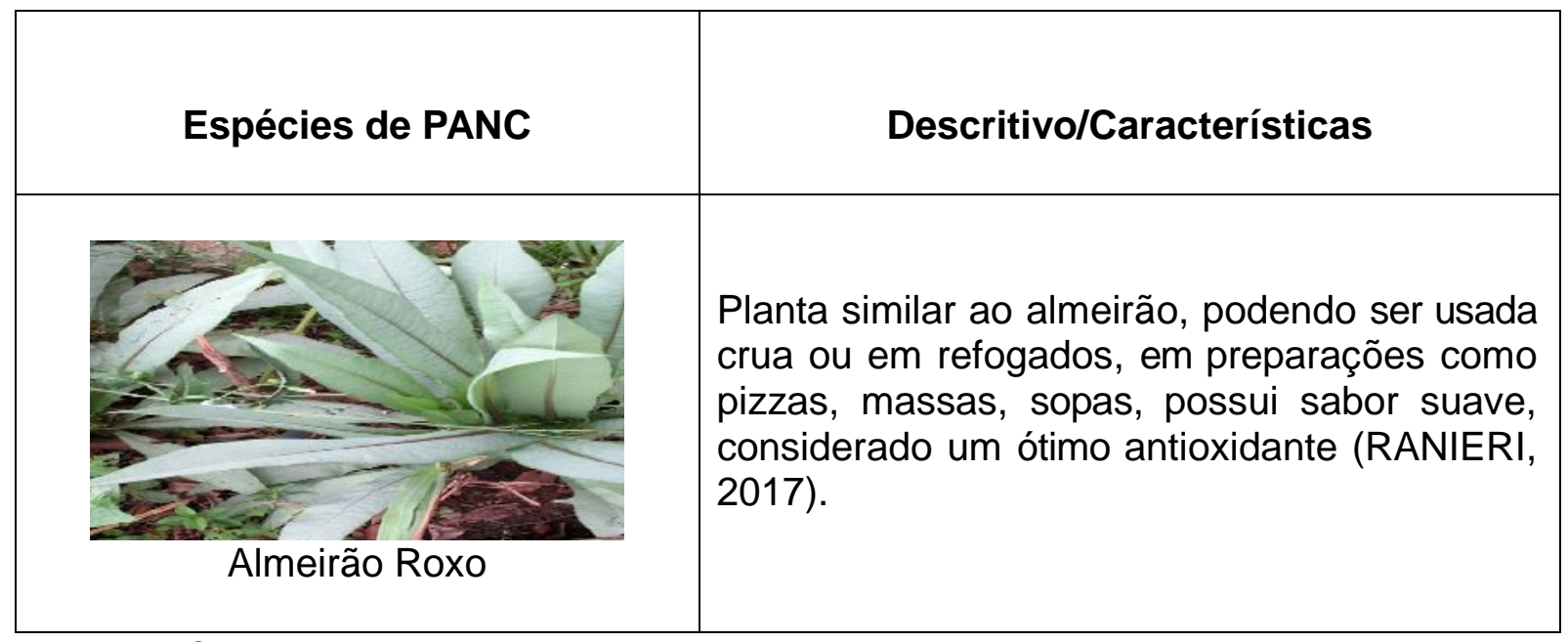




Originária da Índia, esta verdura de folhas
verde-escuro é uma trepadeira com
propriedades medicinais, possui folhas ricas
em cálcio, ferro, vitaminas A, B, B , $\mathrm{B}^{5}$ e C, seu
preparo pode ser feito em refogados, tortas,
sopas ou saladas (RANIERI, 2017).




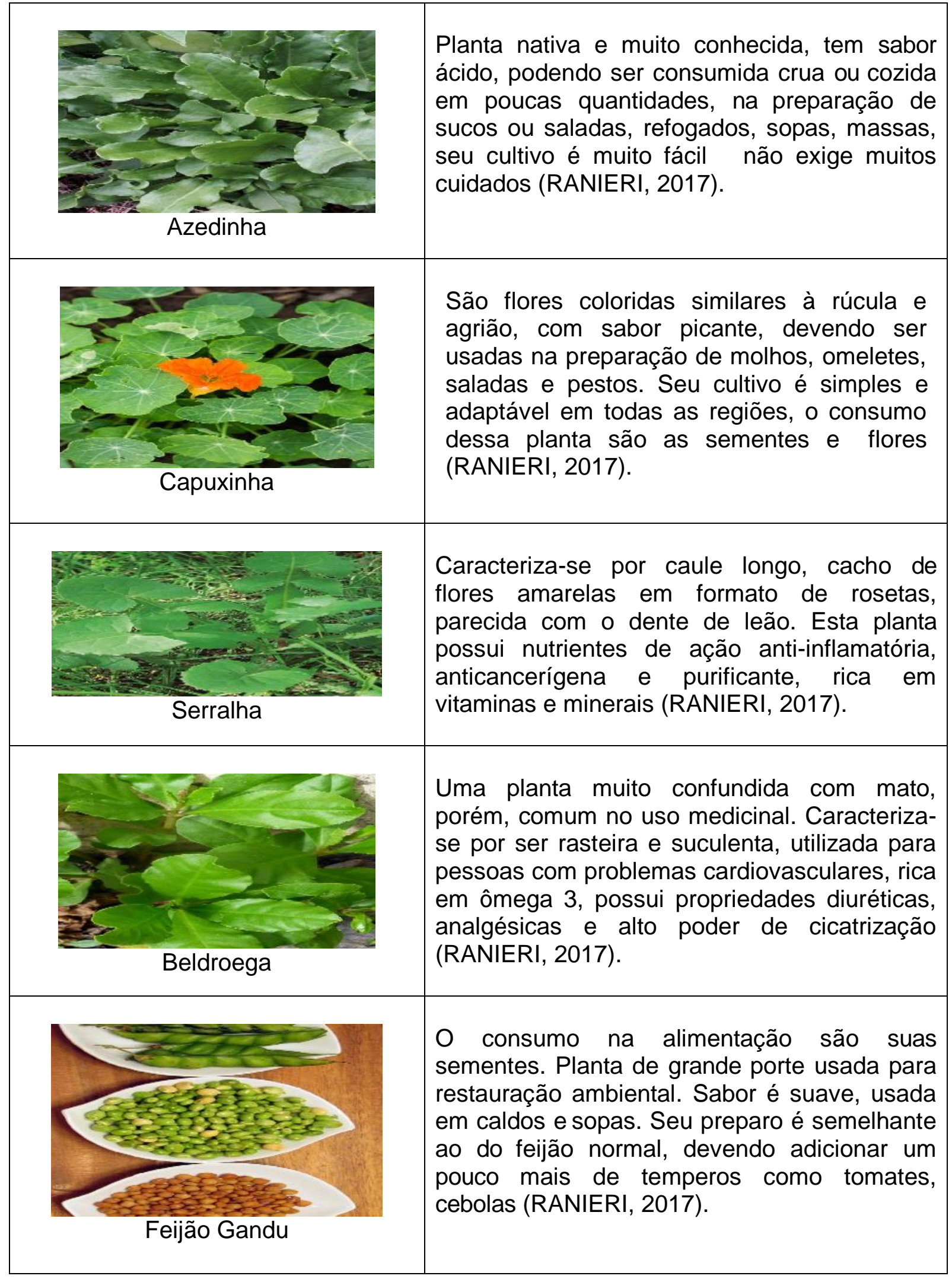




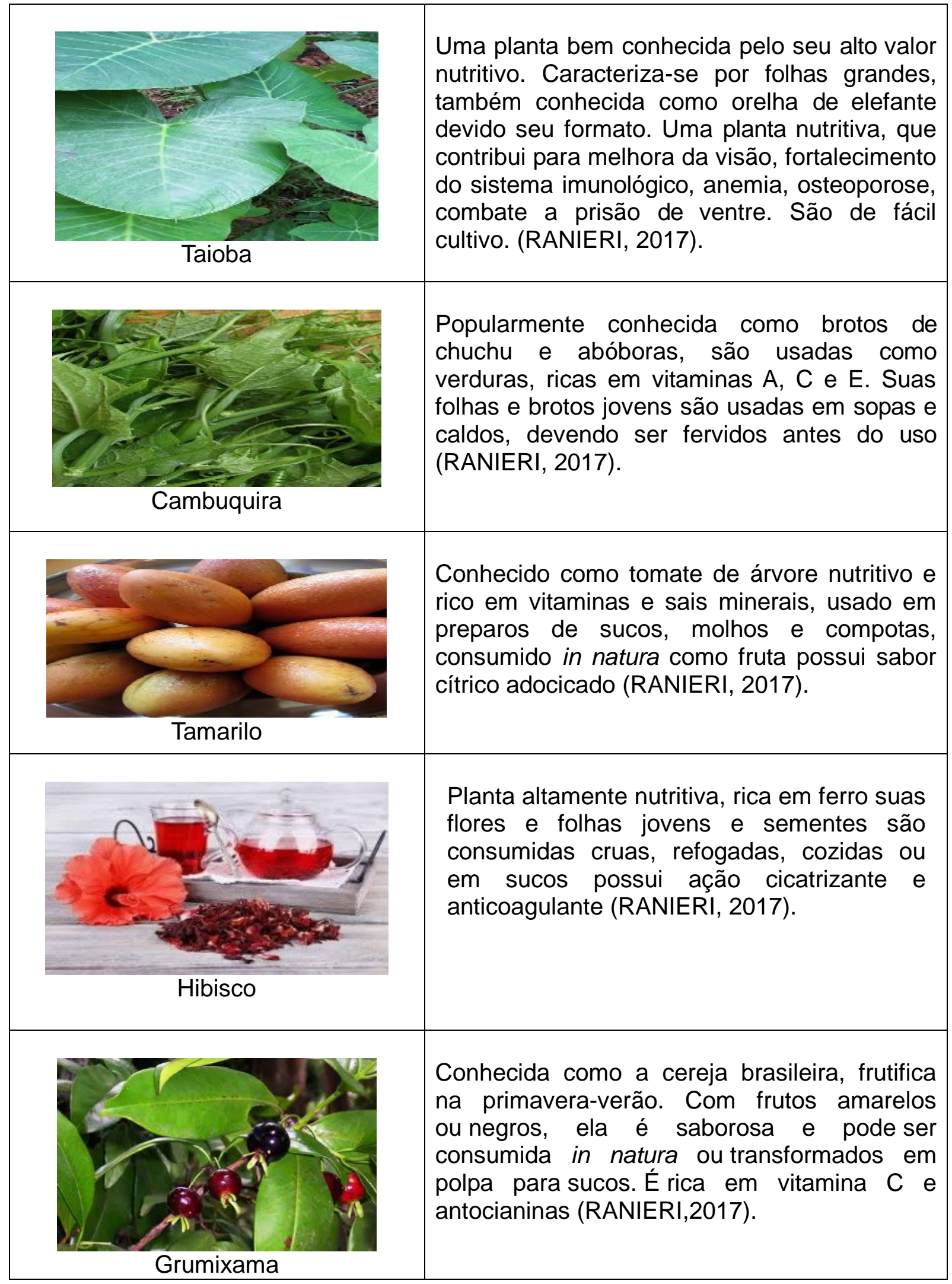




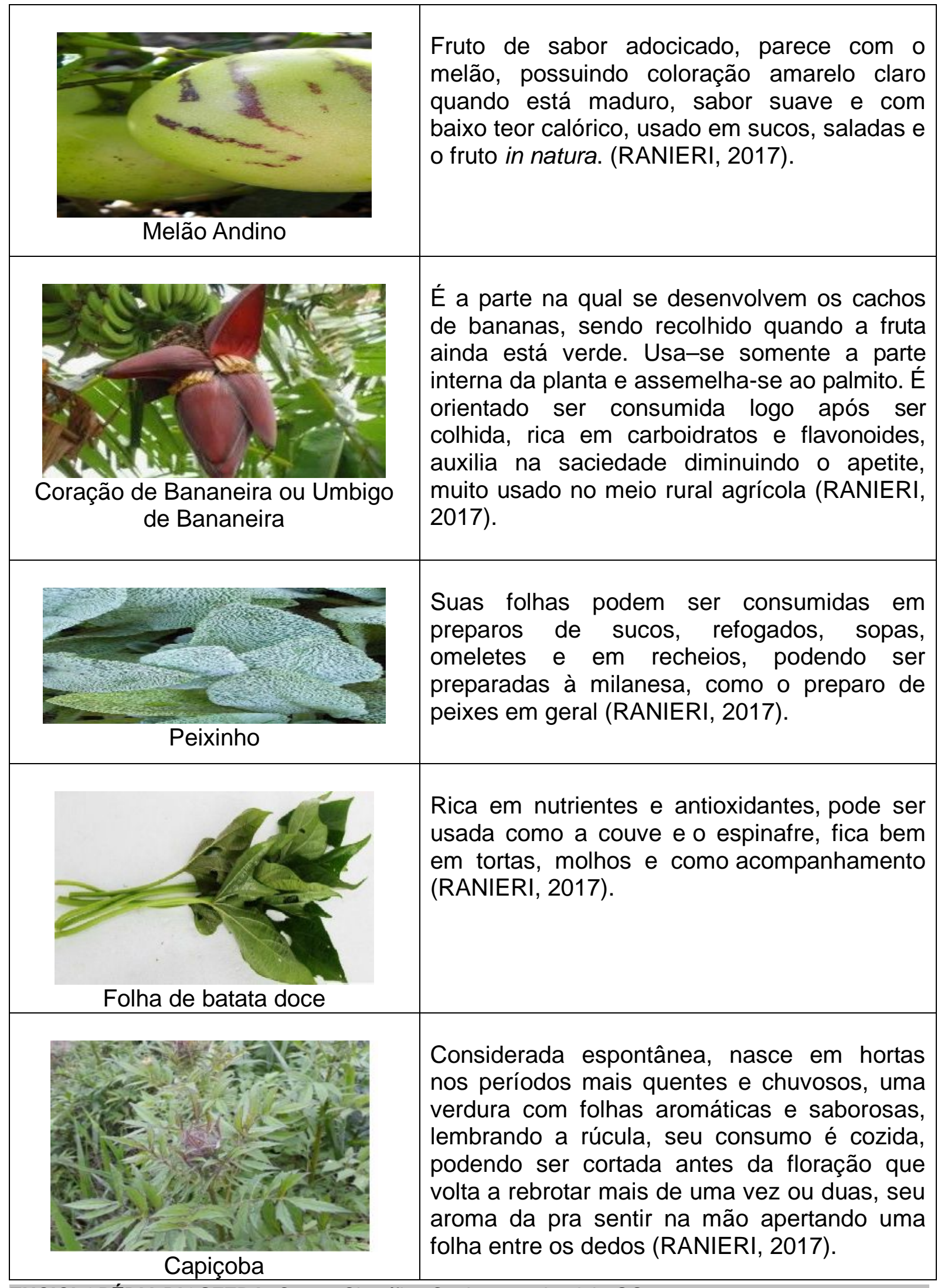




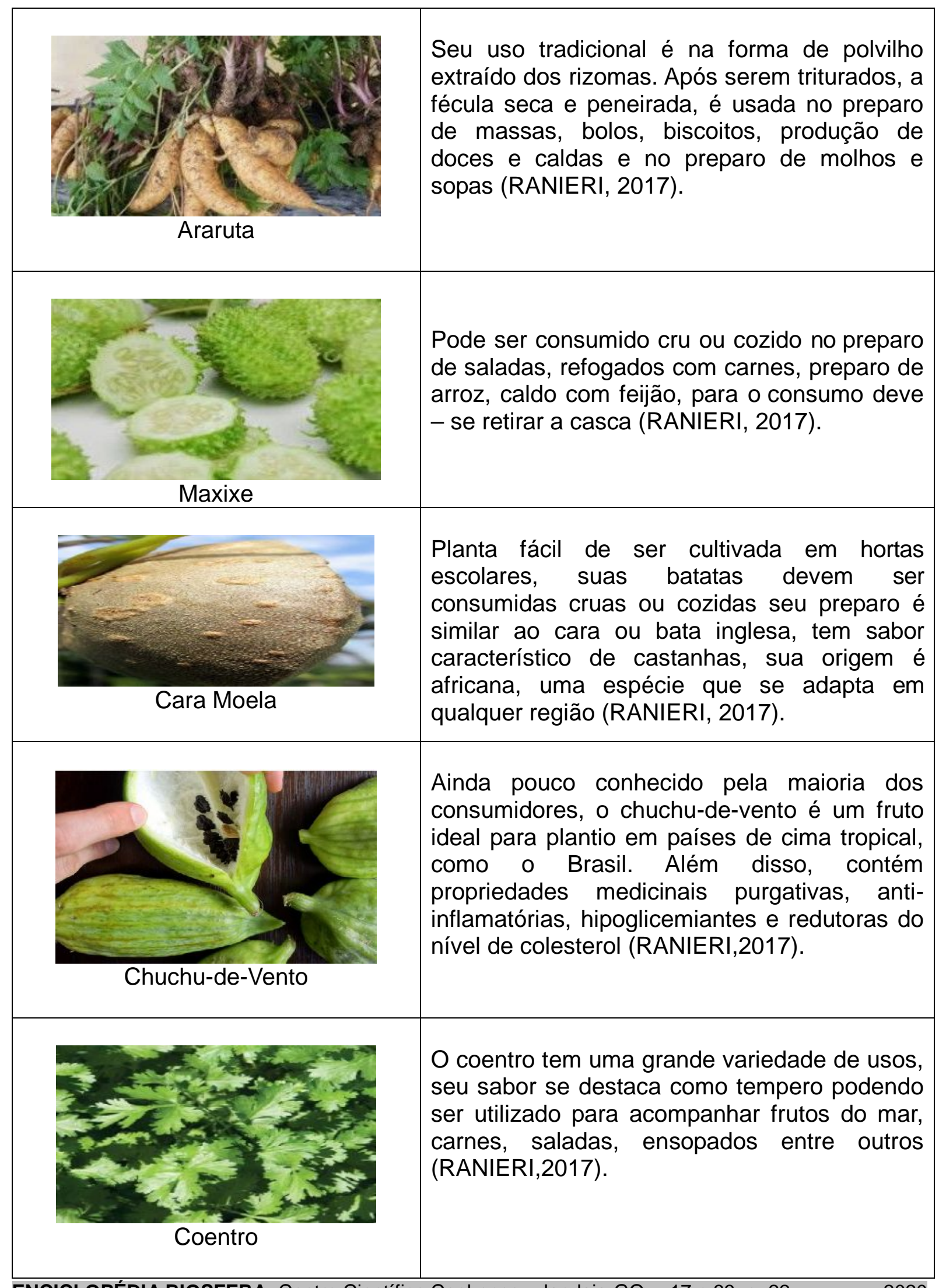




\begin{tabular}{|l|l|}
\hline & $\begin{array}{l}\text { Trata-se de uma planta bastante difundida na } \\
\text { medicina popular para o tratamento de } \\
\text { problemas como gastrites e úlceras. É } \\
\text { possível incluir essa planta em sua rotina } \\
\text { alimentar in natura na forma de saladas ou } \\
\text { então como suco verde (RANIERI,2017). }\end{array}$ \\
\hline Tansagem & $\begin{array}{l}\text { Uma planta versátil no que diz respeito as } \\
\text { possibilidades culinárias começando por suas } \\
\text { sementes que podem ser usadas para } \\
\text { substituir o gergelim em cima de pães. As } \\
\text { folhas apresentam sabor semelhante ao do } \\
\text { espinafre e podem ser refogadas, cozidas ou } \\
\text { empanadas (RANIERI,2017). }\end{array}$ \\
\hline
\end{tabular}

Os processos de revisão bibliográfica se pautaram a partir da junção de palavras e termos chave que se ligaram ao entendimento do que são as PANC, seu valor histórico e cultural junto a população agrícola rural da região, o autor Ranieri (2017) foi um facilitador na compreensão e conhecimento de diversas plantas proporcionando melhor conhecimento sobre as mesmas como pode ser visto no quadro descritivo de diversas plantas encontradas na região.

Esta revisão foi ainda composta por leitura de artigos científicos nas áreas nutricionais de conhecimento cultural, popularização dos saberes sobre plantas medicinais, além de pesquisar a influência de nutricionistas e líderes de cozinha na divulgação dos benefícios de plantas alimentícias não convencionais junto a qualidade de vida. Estudos apontam que a alimentação é uma das necessidades mais básicas e primordiais do ser humano, e considerando de forma crítica a história da humanidade como um todo seria impossível não existir diversos casos de grandes movimentações motivadas integralmente pela busca por fontes de alimentos (MARQUES, 2020).

A busca pelo alimento para sobrevivência, prosperidade, estrutura social ou lucro, perpassa a história de toda a humanidade, embasada no impulso animal da sobrevivência por meio do consumo, porém diferenciada do animalesco por rituais e ideologias que determinam os hábitos alimentares de cada grupo (ALMEIDA; CARVALHO, 2010).

A prioridade na alimentação estabelece uma hierarquia dentro de um grupo social (BAHLS;KRAUSE, 2016), a responsabilidade pela cocção e preparo de alimentos estabelece papéis referentes a status e gênero dentro da sociedade, determinando e reforçando por meio do alimento a função de certos indivíduos (ARAÚJO; TENSER, 2016).

A sociedade se movimenta na busca por alimento e, esta busca por subsistência, uma vez sanada, se torna seletiva, e o ato alimentar toma forma de ritual definindo-se uma cultura real (ARAÚJO; TENSER, 2016). O crescimento populacional urbano cria uma necessidade de mais suprimentos, o cultivo de alimentos extrativismo determina ENCICLOPÉDIA BIOSFERA, Centro Científico Conhecer - Jandaia-GO, v.17 n.33; p. 23 
estruturas e planejamento urbano nas sociedades agrícolas (ALMEIDA; CARVALHO, 2010), a partir de suas necessidades e possibilidades, a sociedade define suas práticas alimentares, e estas então as definem, ambas moldando-se com base em um passado comum.

O líder de uma cozinha ou centro gastronômico juntamente com o nutricionista e equipe de setor tornam-se então mobilizadores cultural sendo definidos como os indivíduos responsáveis pelo planejamento, liderança e poder de decisão, sendo as pessoas de maior importância dentro da cozinha (MICHAELIS, 2019), a posição na qual se encontram dentro das cozinhas da atualidade não como participantes do processo produtivo da indústria alimentícia, mas como o símbolo da vanguarda da gastronomia, esta com a imagem fortalecida pela mídia televisiva, e seguindo uma visão de maior alcance, que busca tornar a alimentação, especialmente o ato de produção, excitante e glamoroso, tornando-o um produto em si (CARMO, 2018).

O indivíduo pode se tornar um influenciador em maior escala, seja por meio do próprio posicionamento ou por meio do conteúdo ofertado, idealmente uma combinação de ambos. O processo de popularização e preservação das PANC é inegavelmente representante da cultura de um povo, sendo conseqüência de fatores ambientais, históricos, religiosos e econômicos (MARQUES, 2020).

As PANC são, em grande parte, elementos integrantes desta cultura alimentar sendo algumas PANC descobertas recentes, como por exemplo, a chamada "maçã de coco" (ATALA, 2013), notória por sua apresentação ao mundo além destas novas adições, tem muitos representantes da cultura alimentar históricas das PANC, preservados pela própria comunidade ou simplesmente pela persistência estas espécies de ocorrência natural (BARREIRA et al., 2015).

Outro papel muitas vezes menosprezado das PANC, especialmente em pequenas comunidades e pendentes da agricultura de subsistência é o combate à fome e desnutrição (PEREIRA et al., 2017). As PANC, especialmente aquelas de alta resistência e ocorrência espontânea, apresentam uma importante suplementação à alimentação de pessoas com carência nutricional, levando a uma maior diversificação de alimentos com potencial ao atendimento as necessidades nutricionais, especialmente considerando o fato de que muitas destas PANC possuem grande quantidade de proteínas (PEREIRA et al., 2017), nutriente de grande deficiência em indivíduos com acesso limitado à proteína animal. As PANC são plantas não usuais, produtos cujas características organolépticas ainda não se integraram ao senso comum, e podem ser confundidas com as diversas plantas tóxicas existentes nos biomas brasileiros (FIOCRUZ, 2016).

Nesta pesquisa foram identificadas 27 espécies de PANC, além de existirem em maior diversidade, são mais popularmente conhecidas na região estudada consumidas com frequência estas plantas mantêm valores cultural e histórico, sendo ainda usadas como plantas medicinais além do reforço alimentar, garantindo um alto valor nutricional e melhorando a qualidade de vida no dia-a-dia.

A utilização de plantas como recursos alimentícios pelo homem ocorre desde os tempos pré-históricos com a utilização de plantas alimentícias, em particular as PANC, é parte da cultura, identidade e práticas agrícolas em muitas regiões do planeta. As PANC estão entre as fontes de alimentos que se desenvolvem em ambientes naturais sem a necessidade de muitos cuidados e grandes áreas. O consumo das PANC pode 
ser estratégia para manter a diversificação alimentar, estimulando a manutenção de áreas destruídas (MARQUES, 2020).

As espécies de PANC são consumidas principalmente de forma refogada (cozida) em molhos e caldos e in natura. Embora sejam espécies não convencionais, algumas dessas encontram-se domesticadas e cultivadas em meio à hortas, pomares ou outras culturas agrícolas, enquanto que as demais são coletadas principalmente em pastos, fragmentos florestais e também em meio à culturas agrícolas.

O contato com outras culturas traz novos insumos, novas práticas e abre mercados, criando a possibilidade de um comércio em maior escala e iniciando o processo de globalização a partir do qual a sociedade se expande e se altera à luz destes novos produtos e conhecimentos. As PANC são, em grande parte, elementos integrantes desta cultura alimentar. Vale salientar que "não convencionais" não quer dizer que tenham sido apenas aquelas abandonadas no processo de massificação da produção alimentar, sendo algumas destas PANC descobertas recentes.

As PANC, especialmente aquelas de alta resistência e ocorrência espontânea, apresentam uma importante suplementação à alimentação de pessoas com carência nutricional, levando a uma maior diversificação de alimentos e potencial de atendimento a necessidades nutricionais, especialmente considerando o fato de que muitas destas PANC possuem grande quantidade de proteínas, a popularização das PANC, tornandoas parte do consumo da população em geral (ANTOINETTE;OLIVEIRA, 2010).

Desta forma, se integrarão na sociedade como um todo e permanecerão vivas na cultura alimentar popular, perpetuando a tradição e a memória que a acompanha. A questão passa, então, a ser como tornar o conhecimento da existência destes insumos parte do conhecimento popular e como ofertá-los à população. A falta de conhecimento quanto ao preparo e poder nutritivo e o abandono das tradições de uso faz com que muitas vezes as pessoas tenham alimentos em seu quintal, ao alcance de suas mãos e os ignorem, comprometendo a nutrição e a segurança alimentar da família.

O distanciamento da prática do uso de PANC na dieta cotidiana alimentar, é um risco à memória e à transmissão dos saberes tradicional às presentes e futuras gerações. Práticas para a expansão do conhecimento sobre PANC são relevantes para a melhora da qualidade de vida da população.

A divulgação e incentivo ao seu consumo como alternativa alimentar democrática, gratuita, com qualidade nutricional, disponível nos quintais e na natureza, importará em uma mudança de hábitos com redução de gastos com alimentação e desperdício de fontes alimentares subutilizadas, o quintal antes visto pelos residentes como mero espaço de cultivo e sociabilidade agora é visto como um espaço de novas sensações, cores, aromas e sabores capazes de garantir não só a soberania alimentar das famílias com o que antes era considerado mato, mas também a reconexão dos moradores com a natureza.

\section{CONCLUSÃO}

Conclui-se que com o crescente aumento no investimento e interesse da população em alimentação além do forte apoio da mídia televisiva na divulgação dessas plantas, essa possibilidade se torna gradativamente mais viável, com um papel social de relevante importância. A criação de uma contracultura à padronização de mercados globais deve vir de uma alteração na própria mentalidade de consumo, e esta pode ser 
motivada de dentro da cozinha.

O conhecimento científico a saberes e práticas populares geradas com grupos sociais numa interação a construção e a organização das informações exigiram uma concepção diferenciada com potencial comercial, criado por um mecanismo autossustentável embasado em um mercado consumidor, criador de demanda e motivador dos processos produtivos e de distribuição.

Os resultados revelam uma fusão de horizontes, uma síntese superior orientada por valores e intencionalidades compartilhadas por grupos em interação e mediados pela ação da comunidade. Assim, acredita-se que em termos de condições sociais, aos grupos que originalmente se envolveram diretamente com os processos de interação da sociedade.

Este estudo da revisão literária apresentou a importância histórica e cultural das PANC e sua amplitude de usos, além de potenciais vantagens para a subsistência de comunidades de baixa renda, como foi observado durante a catalogação e levantamento das plantas popularmente conhecidas na comunidade estudada, contudo, sugere-se ampliar a popularização e preservação dessas plantas devido a sua importância cultural e seu valor econômico.

As reflexões dos autores sobre a inclusão das PANC na dieta alimentar é que as formas de escolha e de consumo de alimentos pelos seres humanos estão ligadas intimamente às suas raízes culturais, valores que estão sendo transmitidos entre gerações, pelo valor nutricional e medicinal.

\section{REFERÊNCIAS}

ALMEIDA, L. Q.; CARVALHO, P.F.; Representações, riscos e potencialidades de rios urbanos: análise de um (des) caso histórico. Caminhos de Geografia, v. 11, n. 34, 2010.

ANTOINETTE, C. J.; OLIVEIRA, L. A.; História e etnografia nativas da alimentação no Brasil: notas biográficas a respeito de um antropólogo provinciano. Imburana, v. 1, n. 2, 2010.

ARAUJO, M. W.; TENSER, C.M.R. Gastronomia: Cortes \& Recortes: $1^{\text {a }}$ edição. Distrito Federal: Editora SENAC, 2016.

ATALA, A. D. O. M. Redescobrindo Ingredientes Brasileiros. 1a edição. São Paulo: Editora Melhoramentos, 2013.

BARREIRA, T.F. PAULA FILHO, G.X.; RODRIGUES, V.C.C.; ANDRADE, F.M.C.; SANTOS, R.H.S.; PRIORE, S.E.; SANT'ANA, H.M.P.; Diversidade e Equitabilidade de Plantas Alimentícias não Convencionais, na zona rural de Viçosa, Minas Gerais, Brasil. Revista Brasileira Plantas Medicinais, v. 17, n. 4, p. 964-74, 2015.

BAHLS, A. A. D. S. M.; KRAUSE, R. W.; Serviços clássicos na restauração comercial: proposta de padronização e esclarecimentos para futuras pesquisas. Revista Brasileira de Pesquisa Em Turismo, v. 10, n. 3, p. 550-573, 2016. 
BRASIL, Ministério do Meio Ambiente. Biodiversidade Brasileira. Disponível em: <http://www.mma.gov.br/biodiversidade/biodiversidade-brasileira> Acesso em: 12 de jul. de 2020.

BRASIL, Ministério do Meio Ambiente. Biodiversidade Brasileira: Avaliação e identificação de áreas e ações prioritárias para conservação, utilização sustentável e repartição dos benefícios da biodiversidade nos biomas brasileiros. Disponível em: <http://www.mma.gov.br/estruturas/chm/_arquivos/biodivbr.pdf> Acesso em: 12 de jul. de 2020.

CARMO, S. G.; Band faz Master Chef aprender mais que novela. Folha Uol. 6 de mar/2018. Disponível em < https://www1.folha.uol.com.br/ ilustrada/2018/03/band-fazmasterchef-render-mais-que-novela.shtml>. Acesso em: 11 de jul. 2020.

CASA E JARDIM ONLINE. Sesc Pompeia promove especial sobre PANC - Plantas Alimentícias Não Convencionais. Disponível em: <http://revistacasaejardim.globo. com/Casa-e-Jardim/Eventos/noticia/2017/10/sesc-pompeia-promove-especialsobrepanc-plantas-alimenticias-nao-convencionais.html>. Acesso em: 12 de jul. 2020.

DORNELES, A. C.; SILVEIRA, B.; PEREIRA, L. Desenvolvimento de horta vertical e compoteira anaeróbica para a agricultura orgânica residencial. Responsabilidade Socioambiental, Ensino, Pesquisa e Extensão. Santa Maria. SEPE. Rio Grande do Sul, Nov. 2011. Disponível em: <https://www.academia.edu/17346109/Desenvolvimento_de_horta_vertical_e_composte ira_anaer\%C3\%B3bica_para_a_agricultura_org\%C3\%A2nica_residencial $>$. Acesso em: 11 de jul. de 2020.

EMBRAPA. Empresa Brasileira de Pesquisa Agropecuária. Visão 2030: o futuro da agricultura brasileira. - Brasília, DF. 2018. ISBN 978-85- 7035-799- 1; CDC 630-799-1.

FIESP. Tendências gastronômicas. Disponível em: <http://www.brasilfoodtrends.com.br/brasil_food_trends/> Acesso em: 11 de jul. de 2020.

FIOCRUZ. Plantas Tóxicas, $2016 . \quad$ Disponível em<http://www.fiocruz.br/biosseguranca/Bis/virtual\%20tour/hipertextos/up2/plantastoxicas.htm>. Acesso em: 10 de jul. de 2020.

IBGE. Sinopse do censo geográfico 2010, Disponível em: $<$ https://censo2010.ibge.gov.br/sinopse/index.php?dados=8>. Acesso em: 10 de jul. de 2020.

IBGE. Sinopse do censo geográfico 2019, Disponível em: $<\mathrm{https}: / /$ cidades.ibge.gov.br/brasil/mg/barbacena/panorama>. Acesso em: 10 de jul. de 2020

KINUPP, V. F.; Plantas alimentícias não-convencionais da região metropolitana de 
Porto Alegre, Editora Plantarum. Ed. 1ํ. v.1. ISBN: 9788586714467, 2007.

MARQUES, G.L. O Processo de Popularização e Preservação das PANC: contexto da modernização. Revista de Comportamento, Cultura e Sociedade, v 8, n. 1, mar/2020.ISSN $2238-4200$.

MICHAELIS. Dicionário da Língua Portuguesa: Chefe. 2019. Disponível em: <http://michaelis.uol.com.br/busca?id=QjZZ>. Acesso em: 10 de jul.de 2020.

PLANO MUNICIPAL DE SANEAMENTO BÁSICO. 2014. Disponível em:<http://barbacena.mg.gov.br/arquivos/PMSB_BARBACENA_VERS\%C3\%83O_PRE LIMINAR_30.01.pdf. Acesso em: 12 de Jul. de 2020.

PEREIRAA, D. P.; SILVA, S.; SANTOS, T. L.; SILVA, J. H. P. Popularização do uso de hortaliças não convencionais: resgate, multiplicação, divulgação e distribuição de propágulos. Revista Cientifica e Tecnológica do IFSULDEMINAS, 2017. ISSN 2319 0124.

RANIERI. G. R., Guia Prático de PANC: plantas alimentícias não convencionais, organização Instituto Kairós, 1a․ ed. São Paulo, Instituto Kairós, 2017. ISBN: 978-8599517-08-6, 17-03716, CDC-581-632.

REVISTA EXAME. Plantas Medicinais: popularização e cultura. Disponível em:< https://www.google.com/search?q\&aqs=chrome.0.69i59j69i57j0l5j69i60.8516j0j4\&sourc eid=chrome\&ie=UTF-8>. Acesso em: 12 de jul. 2020.

SEBRAE. Pesquisa de mercado: Segmentação e seleção de público. Disponível em: < https://www.sebrae.com.br/Sebrae/Portal\%20Sebrae/UFs/MG/Sebrae\%20de\%20A\%20 a\%20Z/Segmenta\%C3\%A7\%C3\%A3o+de+mercado.pdf>. Acesso em: 12 de jul. 2020.

SMERALDI, R. O momento é PANC: evento em Belém joga luz sobre as plantas não convencionais. Disponível em:< http://paladar.estadao.com.br/noticias/comida,omomento-e-panc-evento-em-belem-joga-luz-sobre-as-plantasnaoconvencionais, 70001744820 >. Acesso em: 12 de jul. 2020.

SILVA, A. C. P.; SARTORI, G. V.; OLIVEIRA, A. L. Composição nutricional do coração da bananeira e sua utilização como um alimento alternativo. SaBios-Revista de Saúde e Biologia, v. 9, n. 2, p. 40-45, 2014. 